\title{
Prince Albert and Emma Lake Fungi
}

\section{by Tony Capusten, Prince Albert}

During the spring and summer of 1963 there was more than an average amount of rain in central Saskatchewan and we enjoyed many beautiful and tasty fungi. In May there was the Common Morel, Morchella esculenta, which is prized by gourmets. From the middle of May to July we found numerous white clusters of the edible Clitocybe multiceps and the pale tan goblets of the edible Clitocybe infundibuliformis. In early July we found the edible Boletus edulis and many species of Russula.

On July 28 we found a patch of the poisonous Fly Agaric, Amanita muscaria growing in a spruce wood.

In August we found the Shaggy Mane, Coprinus comatus growing beside the hardest of roadways and sometimes pushing right through the blacktop of the road. From the end of August till the first frost we could find the edible Armillaria mellea, the Honey Mushroom, which is highly prized and is called Pidpanki by Central Europeans.

The Meadow Mushroom, Agaricus campestris, with its pink gills turning brown as they mature and the larger more robust Horse Mushroom, Agaricus arvensis, which may reach a diameter cf ten inches, are both edible. The Field and Horse Mushrooms are both excellent and they

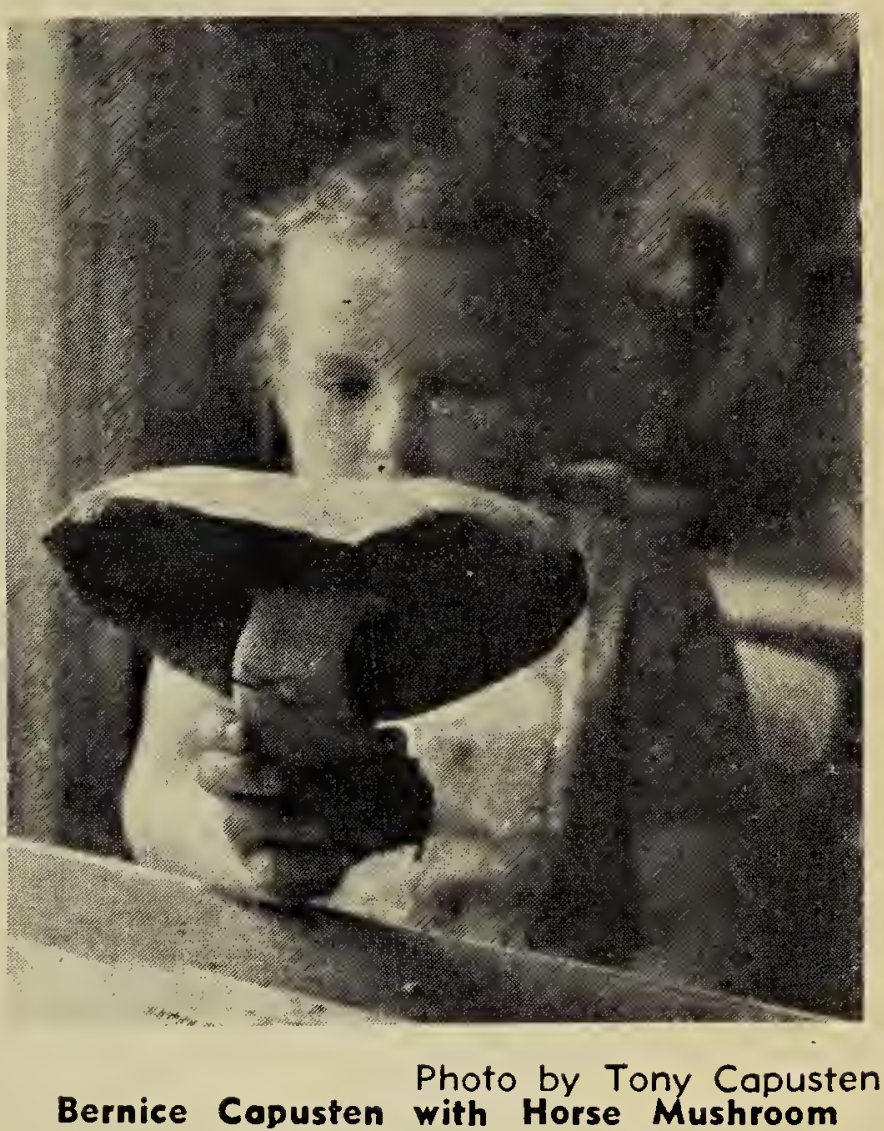

can be used raw in salads. They are found from May to September.

EDITOR'S NOTE: Having enjoyed a delightful meal of Clitocybe multiceps (see back cover of this Blue Jay) at the Capustens, June 25, 1963, I know that Tony is very lucky to have such a cook and I believe that most of us have been missing some interesting experiences by not getting to know the fungi better.

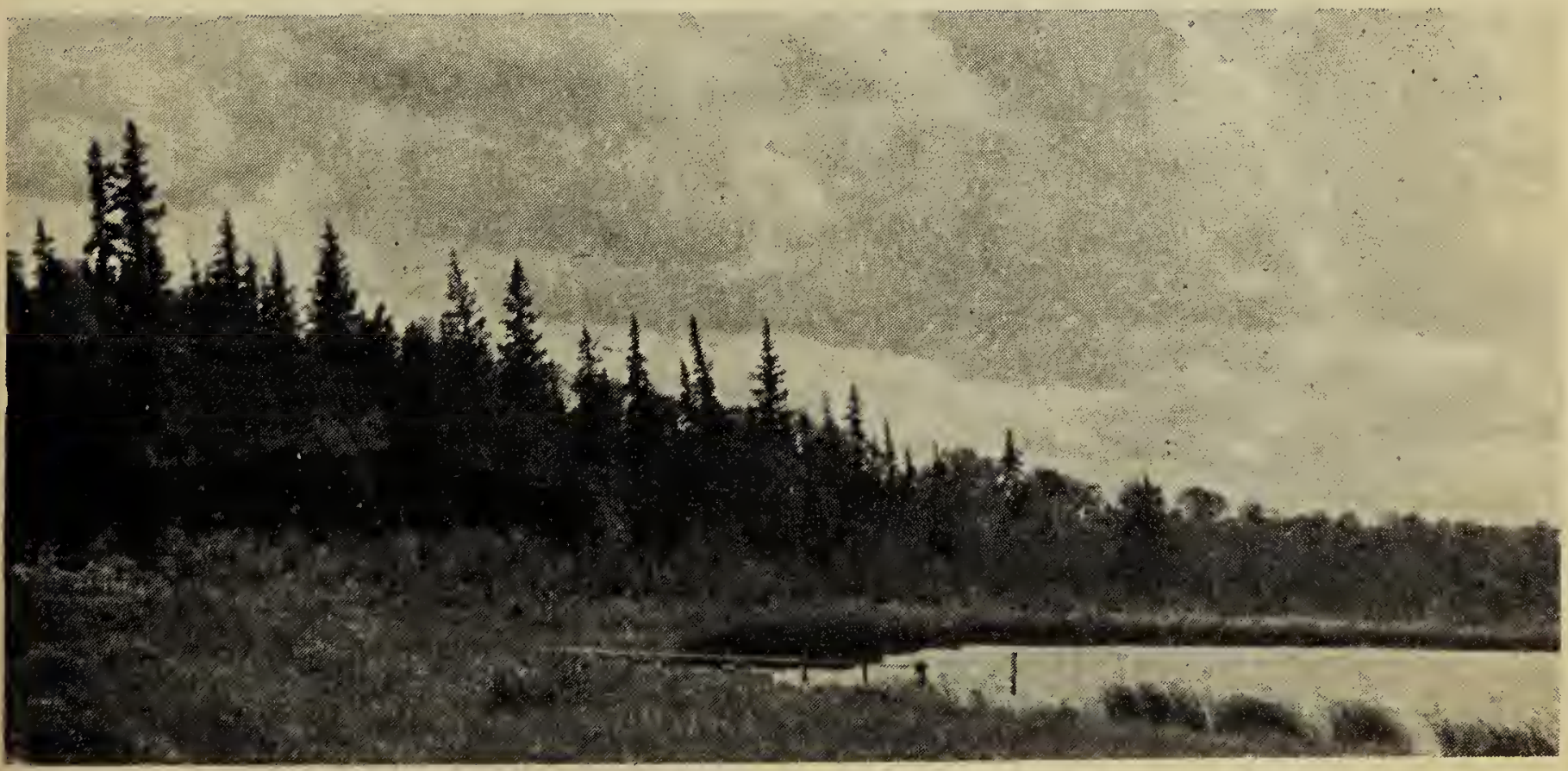

